\title{
Arte, corpo, saúde e cultura num território de fazer junto`
}

\author{
Erika Alvarez Inforsato, ${ }^{\star}$ Eliane Dias de Castro, Renata Monteiro Buelau, Isabela Umbuzeiro \\ Valent, Christiana de Moraes e Silva, Elizabeth Maria Freire de Araujo Lima \\ Universidade de São Paulo, São Paulo, SP, Brasil
}

\begin{abstract}
Resumo
O desenvolvimento de pesquisas e metodologias na interface arte, corpo, saúde e cultura é uma experiência de multiplicidade, produção de corporeidade e cooperação com o território e implica o cultivo de práticas que proponham soluções inventivas para a população envolvida. A experiência aqui apresentada investe em estratégias de atenção e formação em Terapia Ocupacional, pautadas nos conceitos e práticas do corpo, das artes, da produção de subjetividade e da participação social; em diálogo com as políticas públicas de saúde e cultura, a partir da construção de redes, agenciamentos territoriais e circulação de estudantes e da população atendida pela cidade.
\end{abstract}

Palavras-chave: Terapia Ocupacional/educação; corpo; produção de subjetividade; rede arte/saúde/cultura; políticas públicas.

\section{Art, body, health and culture in a territory of doing together}

\begin{abstract}
The development of studies and methodologies in the interface of arts, body, health and culture is an experience of multiplicity, production of corporeity and cooperation with the territory. It implies the promotion of practices that propose inventive solutions for the people involved. The experience presented here invests in strategies of attention and training in Occupational Therapy, based on the concepts and practices of the body, the arts, the production of subjectivity and social participation; in dialogue with public policies on health and culture, based on the construction of networks, territorial assemblages and transit of students and the population assisted throughout the city.
\end{abstract}

Keywords: Occupational therapy/education; body; production of subjectivity; art/health/culture net, public policies.

\section{Introdução}

No tempo e na relação com o trabalho compulsório, encontrar o trabalho possível, pulsante, que faz corpo e dá corpo a conjuntos de exercícios que ocorrem sob protocolos acadêmicos e que escapam a eles. A elaboração processual e a construção coletiva do trabalho de formação que acolhe as condições do momento presente. Inventar saídas que proponham tensionamentos com o modo habitual de produção na universidade é a trajetória do Laboratório de Estudos e Pesquisa Arte, Corpo e Terapia Ocupacional - FMUSP, que tem constituído uma proposta de formação de artistas e terapeutas ocupacionais num território de interface entre as artes, o corpo, a saúde, e a cultura. No cotidiano dessa experiência, articulam-se atividades de sensibilização e experimentações em práticas corporais e artísticas com ações interdisciplinares de construção de redes e cooperação com o território, acompanhadas de estudos que abordam a clínica e a produção de subjetividade numa perspectiva ético-estético-política.

\footnotetext{
^ $\mathrm{O}$ trabalho integrado de ensino, pesquisa e extensão desenvolvido pelo Laboratório de Estudos e Pesquisa Arte, Corpo e Terapia Ocupacional - FMUSP tem recebido apoio e financiamento de diferentes agências de fomento; entre elas: Fundação de Amparo à Pesquisa do Estado de São Paulo (FAPESP), com bolsas de Iniciação Científica, Mestrado e Auxílio Pesquisa; Conselho Nacional de Desenvolvimento Científico e Tecnológico (CNPq), com bolsas de Iniciação Científica; Pró-reitora de Cultura e Extensão da Universidade de São Paulo (USP), com bolsas do Programa Aprender com Cultura e Extensão. Essas bolsas estão associadas à pesquisa "Agenciamento cultural e cuidado às populações em situação de vulnerabilidade social: construção e avaliação de tecnologias socioculturais no campo da terapia ocupacional", que recebeu aprovação do Comitê de Ética em Pesquisa da Faculdade de Medicina da Universidade de São Paulo.

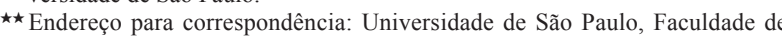
Medicina da Universidade de São Paulo. Rua Cipotânea, 51 (CDP - Terapia Ocupacional). Butantã, São Paulo, SP - Brasil. CEP: 05360160. E-mail: erikainforsato@usp.br, elidca@usp.br, renatabuelau@usp.br, isabelauv@ gmail.com, christiana_moraes@hotmail.com, beth.araujolima@gmail.com
}

As perspectivas, abertas ao campo da Terapia Ocupacional (TO) e das Artes, assumem sentidos múltiplos, pois preparam terapeutas ocupacionais para atuar de forma interdisciplinar, ao introduzir conteúdos transversais à formação em diferentes áreas de atuação, enfatizando a inscrição da TO em territórios culturais e artísticos. Nesse deslocamento, as ações de formação arrastam consigo as populações tradicionalmente fixadas no território de equipamentos e práticas da saúde e tensionam a disposição do campo artístico-cultural a criar condições para esse alargamento de seus contornos. Essa formação implica a produção e o desenvolvimento de práticas que proponham soluções inventivas para as pessoas e grupos em situação de vulnerabilidade envolvidos nessas ações - em sua maioria marcados por experiências com deficiências, sofrimento psíquico e outras situações de ruptura das redes sociais e de suporte. Fica assim, favorecido o acesso a serviços, equipamentos e práticas de arte, corpo e cultura, correspondendo a aspectos sociais e coletivos necessários para dar lugar a novos modos de existir que possam resistir e enfrentar aqueles soterrados pelos funcionamentos predominantes. Numa perspectiva transdisciplinar as ações e projetos construídos na fronteira dos campos das Artes, da Educação, da Psicologia, da Cultura e da Terapia Ocupacional têm por foco: a produção de cultura e subjetividade; o enfrentamento dos processos de institucionalização e de hegemonização dos modos de fazer; e o investimento na instrumentalização crítica em relação às padronizações na cultura, na educação e na saúde que insistem nas especialidades e rejeitam a dimensão múltipla e paradoxal no tratamento à vida. Elementos da clínica transdisciplinar (PASSOS; BARROS, R., 2004), da atenção psicossocial (AMARANTE, 
2007; YASUI, 2009), da produção de subjetividade (PELBART, 2003) configuram-se como contribuições conceituais importantes para a construção dessa proposta de formação e atenção na interface arte, corpo, cultura e saúde (CASTRO et al., 2016).

Para engendrar a formação desenvolvida pelo Laboratório no âmbito da graduação, especialização e pós-graduação, destacam-se os seguintes eixos:

- construção de redes, agenciamentos territoriais e circulação de estudantes e das pessoas e grupos acompanhados nas ações pela cidade, exercitando formas de uma corporeidade no encontro com outros corpos nas vivências do cotidiano;

- produção de experiências e pesquisa de metodologias em corpo e arte para ativar uma sensibilidade estético-clínica que opere aberturas na expressão dos terapeutas e artistas em formação; e

- estudos e exercícios críticos numa perspectiva ético-estético-política, para a construção de uma atuação comprometida com pessoas e grupos em situação de vulnerabilidade no que concerne a conflitos emergentes da atualidade, estratégias políticas afirmativas e proposições de políticas públicas intersetoriais.

\section{Construção de redes, agenciamentos territoriais e circulação de estudantes e das pessoas e grupos acompanhados}

Vai e vem. Bolo, refrigerante, biscoito, bala, café e coxinha. Atravessam a rua, com cuidado para não encostar no ombro de alguém que pode empacar em meio à faixa de pedestres. E vão pro museu, pro centro de treinamento do corpo de bombeiros, pro parque, pro shopping, pra lugar nenhum. Esses vão. Outros toda semana encontram-se, em torno a uma mesa aguardada em disputa num espaço de circulação pública, e trazem lápis, aquarela, papéis de propaganda, fitas colantes, e café. Um dia a garrafa térmica voou porta afora do onibus, numa freada brusca; compraram uma nova! E também de manhã, duas ou três moças estudantes entram numa casa soturna, e uma senhora está pronta na varanda, e outra precisa ser aguardada, com os cabelos desgrenhados, vagando com um pedaço de pão até encontrar o vestido com o qual quer fazer sua aparição naquele dia; tomam o ônibus com a carteira vencida, $e$ contam com a condescendência dos motoristas que gentis as deixam na esquina mais próxima, fora do ponto. E mais, também numa casa em reforma, outra moça estudante, encontra com a mulher que virou criança adequada, educada, que pede autorização pra tomar água e pra pegar o pincel. Elas conversam de histórias que já foram dessa mulher, driblam a insistente interrupção da mãe, vão à biblioteca no parque e muitas vezes saem para um sorvete na rua. E há histórias que estranhamente são passado: um rapaz que fora acompanhado e acompanhou diversas estudantes, dormindo, tomando cafezinho, pintando quadros com cores densas, e pedindo para passar o boneco no pinto; e outro inventor de ideias engenhosas que esticou as bordas da atuação do laboratório até contornos do sistema judiciário reivindicando seu direito autoral; e outro que trabalhava sobre superficies grandes, com desenhos geométricos misteriosos, com cores abertas e que partiu em viagem de fuga com seu cachorro, vagando à pé até a exaustão no prédio da universidade. E tantas e tantos que são a matéria mais intensa e viva que dá consistência e motivo à existência resiliente do trabalho do Laboratório (INFORSATO, 2016).

A consistência que essas imagens assumem nessa narrativa recolhida de variadas situações vivenciadas nos atendimentos, que aparecem em trânsito nas reuniões, supervisões, seminários e discussões coletivas do Laboratório, dão a ver um pouco do exercício de deixar coincidir corpos num território de fazer junto, inventar um corpo comum. É uma tentativa cotidiana, incentivada no âmbito da formação no Laboratório, na perspectiva de cartografar aquilo que se trama no encontro entre estudantes, profissionais e a população envolvida nas ações da vida costumeira. Um registro que traça os percursos que devem menos servir a dar respostas e mais a aplacar o ímpeto intervencionista dos profissionais em ação. Acompanhar esses caminhos, delinear seus mapas, construir marcações sensíveis desses trajetos, conforme o pensamento de Fernand Deligny (apud MIGUEL, 2015, p. 61),

[...] é o modo mesmo de traçar o corpo comum. [...] os mapas não são instrumentos analíticos, nem tampouco de um saber positivo. Os mapas, para falar a verdade, não dizem muita coisa, senão que nós não sabemos, de forma alguma, do que se trata nem o humano, nem o comum. Os mapas são antes dispositivos performáticos e de evacuação: evacuação da linguagem verbal e da angústia terapêutica. Por um lado, os mapas servem para tratar a angústia daqueles que supostamente devem tratar [...].

E se nesse desconhecido somos impelidos pelo enredamento da universidade a realizar projetos, podemos dizer que ocorre aí um agenciamento de redes e a produção de tecnologias socioculturais para o desenvolvimento de práticas de intervenção social correspondendo a demandas deflagradas no campo da saúde, na relação com os direitos sociais, com as estratégias políticas afirmativas e no empenho de produção coletiva da vida.

No caos da cidade, o emaranhado de corpos, as intensidades dos encontros e a vida coletiva imprimem registros que demandam tempo e espaço para serem decodificados e melhor compreendidos. O corpo vibra, produz excitação, contrai-se, quer contato, evita contato, torna-se território de enunciação das experiências, matérias de fabricação de novas vitalidades. Terapeutas, artistas e participantes compartilham a sustentação dos encontros, acolhem as forças que se fazem nos corpos, nos múltiplos aprendizados que se dão em ato e instauram exercícios de cooperação e de produção do comum. A tensão desse esforço faz-se presente na formação, é acolhida pelos supervisores e pelo próprio empenho dos estudantes com sua participação e responsabilização possível no processo. Tarefas exigentes e complexas que demandam muitos cuidados: invenção de práticas, criação de mundos, elaboração de afetos e de experiências de exclusão, que restituem possibilidades de emancipação e vida comum. 
Para a construção e consolidação das ações desenvolvidas são estabelecidas parcerias com equipamentos e serviços da rede pública de saúde e de cultura, projetos autônomos e organizações não-governamentais com finalidade pública. Nesse âmbito, encontram-se práticas em rede que organizam diferentes modalidades de inscrição dos usuários de serviços de saúde na trama sociocultural, ampliando o campo assistencial e experimental e o número de pessoas beneficiadas. Na medida em que o entendimento da dimensão coletiva e pública da intervenção vai entrando em foco, a percepção se amplia e um novo plano de colaboração se estabelece. A formação se faz no estabelecimento de uma posição ética que abre passagens para a vida, instaurando um desafio político de emancipação de todos os envolvidos.

Do conjunto dos projetos que atualmente compõem os cenários de formação prática dos estudantes ligados ao Laboratório, e que potencializam a construção de redes e os agenciamentos territoriais, para efeito deste trabalho, serão destacados o Projeto Cultura Itinerante, o Agenciamento Lapa e a parceria com o Centro de Convivência e Ponto de Cultura É de Lei.

\section{Projeto Cultura Itinerante}

O projeto Cultura Itinerante foi apresentado em 2012 ao Edital da III Chamada de Seleção de Projetos de Reabilitação Psicossocial: trabalho, cultura e inclusão social na Rede de Atenção Psicossocial (RAPS) pelo Centro de Convivência e Cooperativa Parque da Previdência (CECCO Previdência) em parceria com a UBS Jd. Boa Vista, a UBS Jd. São Jorge, o CAPS Butantã e diferentes Laboratórios do Curso de Terapia Ocupacional da Faculdade de Medicina da Universidade de São Paulo (FMUSP). Seu propósito principal é contribuir com a Rede de Atenção Psicossocial na região do Butantã através do fortalecimento e da articulação de experiências e ações culturais já desenvolvidas no território em torno de um projeto comum, que visa potencializar e valorizar os espaços de sociabilidade e trocas, o acesso à cultura e a capacidade criativa de sujeitos e coletivos. Através da implantação de espaços compartilhados de capacitação, discussão e afirmação do trabalho no campo da reabilitação psicossocial, da cultura e das artes o projeto favorece momentos de convivência entre profissionais e usuários, impulsiona o processo inventivo dos grupos envolvidos, investe no repertório de criação e viabiliza o compartilhamento das produções materiais e imateriais da comunidade local. ${ }^{1}$

\section{Agenciamento Territorial Lapa}

A parceria do PACTO com o Centro de Atenção Psicossocial (CAPS) da Lapa, construiu uma cooperação com os terapeutas ocupacionais do serviço e gerou, "uma tessitura complexa de práticas na atenção clínica e formação profissional que interferiu na organização de equipamen-

\footnotetext{
Documento não publicado, elaborado por representantes do CECCO Parque da Previdência, UBS Jd. Boa Vista, a UBS Jd. São Jorge, o CAPS Butantã e dos seguintes Laboratórios do Curso de Terapia Ocupacional na USP: Laboratório de Estudos e Pesquisa Arte, Corpo e Terapia Ocupacional (PACTO); Laboratório de Investigação e Intervenção em Saúde Mental (CONEXÕES); Laboratório de Reabilitação com ênfase no Território (RBC); Laboratório de Estudos em Reabilitação e Tecnologia Assistiva (REATA); Laboratório de Estudos e Ações em Terapia Ocupacional e Gerontologia (GeronTO).
}

tos da esfera pública do território da Lapa" (CASTRO; LIMA; NIGRO, 2015, p. 128). À medida que este trabalho conjunto avançava, outros equipamentos da região foram se articulando numa rede de atenção que incluiu a Biblioteca Municipal da Lapa, o Serviço Residencial Terapêutico da Lapa, a Casa de Cultura Tendal da Lapa, o Cecco Bacuri, o Senac e outros grupos e equipamentos de saúde, educação e cultura da região. A partir daí, constituiu-se o Agenciamento Territorial Lapa, um movimento de conexão para mapeamento de equipamentos da saúde, educação e cultura da região, articulação de redes, estabelecimento de parcerias, discussão e realização de ações de renovação cultural no território. Foram implementadas propostas de oficinas com linguagens artísticas e artes do corpo, grupos de circulação cultural, além de reuniões entre os serviços que compõem o Agenciamento.

Entre as ações desenvolvidas destacamos o projeto Território Cultural, voltado para experimentações de acesso, circulação e apropriação territorial. Coordenado coletivamente pelos estagiários de Terapia Ocupacional, tem a participação de uma população adulta heterogênea, e está voltado à convivência e circulação pelo território, buscando mobilizações com experimentações e intervenções do campo das artes na relação com a cidade e o caminhar, o que ocorre através da circulação por transportes públicos, exploração do entorno, reconhecimento dos trajetos e expansão do repertório de serviços e equipamentos culturais. O projeto investe também na sustentação da experiência nos trajetos e nos locais visitados, traçando redes de pertencimento. Aspectos como a heterogeneidade das histórias de vida, o direito à participação, a intensificação de experiências culturais e o estabelecimento de trocas entre os participantes e a cidade suscitam deslocamentos sensíveis, individuais e coletivos.

\section{Centro de Convivência e Ponto de Cultura É de Lei}

Tessitura gradual e delicada ocorre com a parceria do Laboratório com o Centro de Convivência e Ponto de Cultura É de Lei. O acordo de cooperação faz-se de modo a estabelecer trocas importantes para a formação de estudantes de terapia ocupacional no que concerne ao desenvolvimento de proposições culturais e artísticas públicas e abertas a qualquer um, com foco em criar estratégias para acolher a participação de pessoas em situação de vulnerabilidade associada ao uso de drogas, com destaque para a população em situação de rua. As atividades compõem estratégias de Redução de Riscos e Danos associados ao uso de drogas e acontecem no Ponto de Cultura É de Lei, localizado no centro da cidade de São Paulo e em diferentes espaços públicos da cidade. Desde 2013, os estudantes do Laboratório compõem as equipes do núcleo de cultura para acompanhamento de ações de criação em linguagens artísticas; agenciamento de processos coletivos de produção cultural e cultura digital; apropriação do território da cidade e articulação de coletivos. O Laboratório também tem oferecido um espaço de assessoria à equipe de Práticas de Redução de Danos, para encontrar elementos analisadores que modifiquem as configurações centrais, desnaturalizando processos, e 
verificando nas circunstâncias atuais da instituição, modos de minimizar o sofrimento no cotidiano de trabalho e potencializar o projeto coletivo.

Nos três projetos acima descritos o adensamento de conceitos e práticas do corpo, das artes e da cultura, tanto nos atendimentos quanto na formação, colocam em operação a produção de conhecimentos e afetos que instauram um território de confiança para a produção da saúde e dos direitos de participação sociocultural. O cotidiano das práticas busca restaurar uma corporeidade porosa e sensível nos modos de se comunicar, de cooperar, de viver junto.

\section{Produção de experiências e pesquisa de metodologias em corpo e arte na formação em Terapia Ocupacional}

O Laboratório, através de seu projeto didático-assistencial PACTO, investe na produção de experiências e pesquisa de metodologias em corpo e arte para ativar uma sensibilidade estético-clínica que opere aberturas na expressão dos terapeutas e artistas em formação.

Foram produzidas estratégias a partir de relações conceituais com a filosofia - política e estética -, a psicologia e a sociologia, especialmente, em exercícios de nomeação, descrição e interlocução que sustentam a experimentação e o desenvolvimento de suas ações clínicas, artísticas e culturais com a população atendida, os profissionais e estudantes envolvidos. Para tanto, experiências de acompanhamento combinam-se com experimentações estéticas que possam dar lugar a afetos e marcas produzidos nos encontros e, ao mesmo tempo, oferecer ferramentas para a instauração de processos de criação que possibilitem a aprendizagem e a passagem desses afetos do plano das forças ao plano das formas. Neste artigo, serão apresentadas, como exemplos, as estratégias dos Experimentos Estético-Clínicos e dos Encontros de Sensibilização em Artes.

\section{Experimentos Estético-Clínicos}

Diversos formatos têm sido adotados para estreitar o enlace entre a assistência/mediação nos projetos e a pesquisa/registro na formação profissional. Cadernos de campo, diários de campo, cadernos de artista - instrumentos das artes, do corpo, da antropologia, e da clínica foram empregados para buscar esta aproximação (DUARTE; INFORSATO, 2011).

O experimento estético-clínico é, neste sentido, uma proposta de registro que conjuga exercícios a partir de estratégias clínicas do campo da Terapia Ocupacional, de operações estéticas do campo das artes e de práticas corporais visando aproximações com a região indeterminada entre estes territórios, a saber, as estratégias estéticas da TO e as operações clínicas das artes e do corpo. Este embaralhamento que a zona fronteiriça destas áreas apresenta é tomado como uma convocação sensível para que cada estudante possa investir na busca pela melhor expressão dos acontecimentos de sua prática, das marcas e dos afetos que pedem passagem em seus corpos.
A expressão é aquilo que faz ponte, caminho entre os eventos e seus elementos constitutivos, que faz uma junção temporária para acomodar o que vem. Não se trata de explicar, interpretar, nem de revelar. "Uma expressão é tanto melhor quanto mais nos incita a pensar o que ainda não foi pensado através do que se tem por adquirido, e ela só se mantém viva ou em uso porque através dela ainda nos ligamos ao mistério do exprimido" (FURLAN, A.; FURLAN, R., 2005, p. 32). Diferentemente da representação das vivências, a solicitação é por uma forma que possa dar importância aos acontecimentos, um continente que funcione favorecendo o acompanhamento dos processos, onde as experiências possam pousar e seguir seu incômodo, sua indagação, indicando outros acontecimentos. O próprio experimento estético-clínico inventa um novo processo, a partir da recombinação do vivido.

Produzido conjuntamente e atrelado aos demais procedimentos (supervisão, práticas grupais nos projetos acompanhados, ateliês, orientações, estudo e visitas), os experimentos-estéticos clínicos devem compor uma rede aguda para que a distância entre a assistência/mediação nos projetos e a pesquisa/registro na formação profissional se ajuste. No decurso do processo formativo, cada estudante prepara este experimento ao modo de uma cartografia: encontrando formas provisórias para "a rede de forças" à qual a prática em questão se encontra conectada, "dando conta de suas modulações e de seu movimento" (BARROS, L.; KASTRUP, 2009, p. 57). O resultado deve funcionar como registro do período em que se dá o percurso da prática, e as sensações são seu ponto de partida, com o objetivo de construir um território com várias teias, suficiente para dar consistência às experiências vividas naquele momento. As sensações referem-se não só aos órgãos do sentido, mas principalmente à sensibilidade e ao pensamento produzidos no contato com os elementos implicados nas práticas de formação e com outras regiões da vida que a elas possam associar-se de modo livre e atemporal.

Cada experimento estético-clínico é desenvolvido em continuidade, sob etapas definidas para as apresentações. Neles devem constar descrições das situações, elaborações, associações, comentários, citações, referências, grafismos, pinturas, colagens, cópias, fotos, dobras, texturas, gestos, ritmos etc., que mantenham algum tipo de relação com o vivido. Em cada apresentação do material para apreciação ocorre uma interlocução/devolutiva na forma de um exercício crítico coletivo que contribui construindo parâmetros e destacando pontos de força.

\section{Encontros de Sensibilização em Artes}

A necessidade e o desejo de estudar, conhecer e inventar tecnologias de potencialização da participação sociocultural capazes de diluir as imagens mais estereotipadas em relação às populações comumente atendidas pela Terapia Ocupacional, evitando as habituais arbitrariedades que observamos na maioria dos espaços sociais e fortalecendo ações em que as questões das artes e do corpo possam servir àquelas da vida, mobilizou a proposição de encontros de sensibilização em artes na formação. 
O Laboratório experimenta diferentes composições e proposições que viabilizam a pesquisa em torno dessas estratégias, tais como: ações que tocam o campo da performance e exercitam o caminhar pela cidade como uma prática estética; apresentação e discussão de referências do universo das artes e do corpo; visitas técnicas a museus, galerias, ateliês e espaços culturais; e construção de narrativas de cenas vividas a partir de procedimentos literários.

Entre essas proposições, também foram desenvolvidos projetos voltados às questões da mediação em artes com o Museu de Arte Contemporânea da Universidade de São Paulo (MAC/USP), a Fundação Bienal de São Paulo e o Paço das Artes, nos quais estudantes e terapeutas acompanharam percursos de grupos em visita guiada por educadores das instituições - com prioridade àqueles com populações de serviços de saúde e assistência social. Essas parcerias foram multiplicadoras de um contato entre diferentes saberes de maneira cuidadosa e acompanhada para a constituição de novos modos de atuação e intervenção junto às populações que acessam e devem acessar os espaços e equipamentos de arte e cultura. Nessas ocasiões, o trabalho requereu um esforço interdisciplinar para a construção de respostas mais complexas às demandas das populações atendidas pela Terapia Ocupacional, aos diversos frequentadores desses espaços, às questões mobilizadas pela arte contemporânea e aos atravessamentos institucionais e seus contextos de inserção. No cruzamento dessas forças, acentua-se na mediação sua função crítica e política, no sentido de pensar-se "como uma negociação entre interesses diversos, sem nenhum poder conciliatório, e que não se exime de evidenciar seus próprios interesses e contradições" (HONORATO, 2009, p. 61).

\section{Estudos e exercícios críticos numa perspectiva ético-estético-política}

Diante de uma série de movimentos políticos que visaram alterar o cenário de participação social de pessoas antes restritas a instituições fechadas (pessoas com deficiência, com doenças degenerativas, com histórico de sofrimento mental e/ou em situação de vulnerabilidade social) inaugura-se contemporaneamente um panorama ético-político. Algumas oportunidades começam a estruturar-se através de políticas públicas e legislações que estabelecem novos funcionamentos sociais, a partir da exigência de composição entre diferentes setores da sociedade.

A instauração desse panorama ético-político pede a construção de ferramentas conceituais que permitam pensar os acontecimentos e localizar as ações de Terapia Ocupacional nas configurações atuais, numa perspectiva de problematização do presente e de construção de uma atuação comprometida com os direitos e com a proposição de políticas intersetoriais. Isso exige da formação a imersão num universo conceitual que possibilite a aproximação ao campo da prática com olhar crítico e atento às diferenças que se fazem no cotidiano dos serviços, nos projetos e nos modos de levar a vida.
No âmbito deste eixo, apresenta-se abaixo a estratégia dos Grupos de Estudos e Seminários - que favorecem o exercício crítico na relação com a profissão - e o Grupo de Trabalho Arte, Saúde e Cultura, que se configura como uma contribuição do Laboratório, junto a parceiros da rede de arte, saúde e cultura, na proposição de políticas públicas intersetoriais compromissadas com os direitos das populações atendidas.

\section{Grupos de Estudos e Seminários}

Os grupos de estudo configuram-se para criar condições aos estudantes/profissionais de construírem um trânsito por elementos conceituais que favoreçam a constituição de um corpo de referência para as práticas desenvolvidas no campo da Terapia Ocupacional em sua interface com as artes, o corpo, a cultura, a clínica, o campo social e a educação. Através do estudo de temáticas transversais, a leitura dos textos selecionados é acompanhada da preparação de diagramas conceituais e do levantamento de questões que subsidiem as discussões coletivas orientadas. Os diagramas devem articular os conceitos-chave dos textos, privilegiando zonas de contato entre eles. Por conceitos-chave consideraremos: palavras, expressões e até mesmo citações, que devem ser conectadas por meio de setas, flechas, linhas, pontilhados, sobreposições, cores, fitas, sinais, grafismos etc. Comentários, observações breves, indicações e legendas podem ser acrescentados. Cada conceito-chave deve ser pensado e assinalado em relação aos demais através de indicações de bifurcação, tangência, avizinhamento, transversalidade, conexão, diferenciação, ruptura, implicação, coexistência etc. O objetivo é traçar um panorama da compreensão de cada estudante, evidenciando perspectivas convergentes, dissonâncias e complementaridades no contato com os materiais teóricos apresentados.

Nesta direção ocorre também a preparação pelos estudantes de seminário coletivo com apresentação oral e escrita para as equipes, de forma a produzirem uma contribuição ativa para os profissionais com quem desenvolvem as práticas. Esta tarefa configura-se como exercício de exposição dos entendimentos e questionamentos decorrentes das concepções dos projetos e da extensão das ações desenvolvidas pelo PACTO. Para o seminário devem convergir as articulações com os espaços de discussão coletiva, as leituras e interlocuções que acontecem nos espaços de supervisão, coordenação e formação. A temática é selecionada de modo a contribuir com as discussões da equipe, e agregar perspectivas para análise das situações relacionadas aos respectivos campos de ação e pesquisa. Com isso, oferece-se aos estudantes a possibilidade de compartilharem o estudo atualizado da bibliografia, numa operação processual, com um pensamento em trânsito que acompanha o movimento de um trabalho em desenvolvimento. A bibliografia, revista e atualizada semestralmente, é definida levando-se em consideração as experiências clínicas, políticas e institucionais implicadas neste trabalho de interface e o ponto de problematização que as ações dos profissionais enfrentam, de modo a apresentar ao profissional em formação o solo conceitual que sustenta as práticas e as pesquisas do Laboratório. 
Acompanhar as ações de sujeitos com histórias complexas implica, nos termos de Foucault (1984/2004), no exercício de pensar diferentemente, e remete a um campo de inventividade a partir do acesso às múltiplas perspectivas que os diferentes campos do conhecimento podem proporcionar. Assim, os textos indicados são provenientes de diversos campos de saber que tangenciam as fronteiras das Artes, da Terapia Ocupacional, da Educação, da Filosofia e da Saúde. Isto envolve temáticas pautadas na contextualização histórico-conceitual da utilização das atividades artísticas e práticas corporais no campo da saúde, no conhecimento de aspectos relacionados à estética e história das artes, na compreensão das relações entre processos de criação e processos de subjetivação, nos estudos da corporeidade e das abordagens corporais, na construção de conhecimento técnico e metodológico nestes campos, nas produções textuais recentes da TO que se aproximam das propostas do PACTO e, em uma contextualização mais ampla, do encontro entre práticas clínicas e sociais (CASTRO et al., 2009).

\section{Grupo de Trabalho Arte, Saúde e Cultura}

A partir da mobilização de projetos, grupos e experiências dos serviços públicos de saúde e cultura, da sociedade civil e da universidade em direção às Secretarias Municipais de Saúde e Cultura, surgiu, no início de 2014, o Grupo de Trabalho (GT) Arte, Saúde e Cultura. Atualmente composto por gestores, trabalhadores, representantes da universidade, da sociedade civil e da Câmara Municipal de São Paulo, este grupo busca construir estratégias para a criação de políticas públicas situadas em territórios de fronteira entre as artes, a cultura e o campo social que potencializem a produção de saúde e cultura e ampliem a rede de diálogo interdisciplinar e intersetorial no município de São Paulo.

Este investimento do GT parte da percepção de que as experiências que acontecem na interface desses campos de intervenção e conhecimento se potencializam mutuamente e contribuem para a produção de saúde, cidadania, participação social e fortalecimento cultural. Identifica-se a necessidade de fomentar e ampliar estratégias que promovam a interdisciplinaridade e a sinergia de políticas públicas intersetoriais, favorecendo, prioritariamente, o encontro com a diferença e a ampliação de espaços de convívio e criação que não se reduzam a princípios culturais, artísticos, de saúde e/ou sociais hegemônicos, e sustentem a chamada diversidade cultural, para além de categorias específicas, sejam elas sociais, diagnósticas, identitárias, étnicas, geracionais, etc. O GT parte do reconhecimento de que o convívio com a diferença, a acessibilidade e o exercício no campo cultural requer o investimento de diversos agentes e equipamentos trabalhando em parceria com o intuito de ampliar os espaços de pertencimento das populações que têm sua circulação frequentemente restrita aos equipamentos de saúde e/ou assistência social e, simultaneamente, exige um distanciamento do uso instrumental da arte e da cultura que comumente ocorre nas ações destinadas a essas populações. A chegada e sustentação das pessoas com deficiências, sofrimento psíquico e/ou em situações de vulnerabilida- de aos equipamentos de cultura não costuma se dar de forma espontânea e imediata devido aos diversos impedimentos físicos, sociais, econômicos e simbólicos que elas enfrentam cotidianamente. $\mathrm{O}$ encontro com a diferença produz mobilizações e tensionamentos nem sempre fáceis de serem manejados, mas não por isso devem ser neutralizados. Ao contrário, essas situações interessam do ponto de vista de ações éticas, comprometidas com a vida e os direitos humanos.

A urgência de uma articulação intersetorial para a proposição de políticas públicas mais transversais intensifica-se no fato de que as experiências profícuas do ponto de vista do encontro com a diferença e do trabalho desenvolvido na interface das artes, da saúde e da cultura geralmente dependem, quase que exclusivamente, da sustentação individual e militância de alguns profissionais - o que coloca essas iniciativas em uma situação de fragilidade incompatível com a necessidade destes espaços na cidade.

Dentre as ações já realizadas pelo GT, destaca-se o "I Encontro Arte, Saúde e Cultura - construindo uma política Municipal de interface" (LOPES; VALENT; BUELAU, 2015), na Praça das Artes - que contou com a participação de aproximadamente 200 pessoas de diferentes territórios da cidade, reunindo gestores, trabalhadores, usuários, estudantes e pesquisadores, bem como o Secretário Municipal de Cultura e o Secretário Adjunto da Saúde em exercício naquele momento; o "I Encontro entre Centros de Convivência e Cooperativa, Casas de Cultura e Pontos de Cultura", no Centro Cultural São Paulo; e o "II Encontro entre Centros de Convivência e Cooperativa, Casas de Cultura e Pontos de Cultura", na Câmara Municipal de São Paulo - com a presença de gestores e trabalhadores vinculados a esses equipamentos nas diferentes regiões da cidade de São Paulo. Nos três eventos foram levantadas fragilidades, potencialidades e propostas para ações nesse campo de interface, de forma a contribuir para a elaboração de uma Política Municipal de Interface. O GT também contribuiu, na etapa de consulta pública, com a construção do Plano Municipal de Cultura da cidade de São Paulo (2016), propondo ações práticas de sustentação e formação para o trabalho da cultura na interface com outras dimensões da vida.

O acúmulo de discussões a respeito deste campo coloca o GT em condições de contribuir com a proposição de políticas públicas intersetoriais que incorporem a ética de respeito e valorização da diferença como princípio transversal, e de propor ações práticas que possam oferecer condições efetivas de sustentação e formação para o trabalho na cultura em interface com outras dimensões da vida. ${ }^{2}$

\section{Um corpo que cria comum num território de fazer junto}

A dimensão investigativa e exploratória do trabalho desenvolvido no PACTO o situa num território no qual as questões são abordadas num recorte que considera a formação dos profissionais, a população atendida, a es-

${ }^{2}$ Foram utilizadas para a elaboração deste item as informações contidas em documentos não publicados, produzidos pelos integrantes do GT, tais como "Documento do GT Arte, Saúde e Cultura aos responsáveis pela elaboração do Plano Municipal de Cultura da cidade de São Paulo" (2016) "Carta à Comissão de Educação, Cultura e Esporte da Câmara Municipal de São Paulo" (2016). 
truturação e o funcionamento dos projetos, as redes de suporte, as produções artísticas, as manifestações corporais e as relações da TO com o campo artístico-cultural. Considerando que o contato com as populações em situação de vulnerabilidade solicita uma abordagem clínico-política em que devem ser considerados os efeitos dos funcionamentos sociais sobre os corpos e sobre a vida, bem como os deslocamentos destes funcionamentos e a instauração de outras políticas de subjetivação.

A experiência proposta aos estudantes, de participação nos projetos coletivos e nos Encontros de Sensibilização, acompanhamento das ações do GT Arte, Saúde e Cultura, realização dos Grupos de Estudos, Seminários e Experimentos Estético-Clínicos, provoca efeitos transversais em sua formação. O trabalho territorial, o contato com a população atendida, o exercício crítico do pensamento e a abertura para uma sensibilidade estético-clínica levam à construção conjunta de modos de exploração da cidade e do cotidiano, em função de demandas detectadas ou inventadas, a fim de fortalecer os vínculos com a própria vida. Esses trabalhos traduzem-se em registros de pontos relevantes de aproximação entre as artes, o corpo e a saúde nesses processos.

A efetuação destas experiências se dá nos corpos: de cada estudante, participante ou profissional em exercício e em formação, de modo a compor densidades de assimilação coletiva dos acontecimentos. Considerando a proposição deleuziana que a partir de Nietzsche diz que o corpo é a desigualdade de tensão entre forças (DELEUZE, 1976, p. 33), num espaço de escuta crítico e analítico, cada interrogação que se produz diante das vivências cotidianas faz emergir elementos passíveis de confusões, dá lugar a constituição de instrumentos de apreciação e manejo dos encontros/combates na interface da clínica com as artes e a cultura e proporciona uma consistência para os corpos implicados nessas ações.

Um corpo é um processo aberto em formação contínua, oscilante, que des-estrutura toda forma a priori de fundamentação. Um corpo é um fluxo constante de forças diferentes em relação dis-funcional com outros corpos, mas sempre é uma totalidade inacabada e incompleta. Devido a isso, não é possível delimitar, definir, identificar de antemão o que é um corpo. O corpo se subtrai aos limites do pensamento representativo, dado que um corpo é sempre possibilidade de realizar diferenças sempre novas, mas um corpo é sempre mais do que realiza, é um campo de forças gerativas e produtivas [...] atualizando-se sem esgotar seu poder de transformação (EMANUEL ESPERÓN, 2013, p. 23).

A experiência de múltiplos corpos compondo com um trabalho de instauração de um plano de possibilidades expressivas e sociais afere uma luta coletiva, generosa, pois abre caminho para muitas trocas e aprendizados de formas coletivas de existir, articulando presenças, proximidades, condições de possibilidade e pertencimento. O saber do corpo se faz presente nas ações, reposiciona modos de funcionamento da subjetividade, mapeia as formas de vida e os acontecimentos do mundo.
Com isto, contemplam-se aspectos da produção de subjetividade - que se distinguem da apreensão subjetiva ou objetiva de fenômenos -, ao considerar a instauração de modos de sentir, agir e pensar agenciados pela multiplicidade de forças (a história e a necessidade das pessoas e grupos e as situações de vulnerabilidade, as políticas públicas, os panoramas históricos, os sistemas econômicos, os direitos civis, as ciências, as artes, os esforços para a construção do comum, etc.) atuantes na vida das populações atendidas pela TO e verificadas no decorrer do trabalho do PACTO.

Corroborando a enunciação de Spinoza (2009, p. 64), quando diferentes corpos se movem de modo a se comunicarem e transmitirem seus movimentos uns aos outros, podemos dizer que esses corpos compõem, juntos, um outro corpo. Nesse sentido, entendemos que, de todas essas ações do PACTO se depreende um corpo coletivo multifacetado, formado por outros corpos que, em relações de composição, afetam-se mutuamente por suas velocidades e lentidões; um corpo que busca perseverar e aumentar sua capacidade de agir, cuja potência emerge das relações de força que o constituem e de sua capacidade de criar conexões e multiplicá-las. Um corpo feito de corpos que coincidem num território de fazer junto.

\section{Referências}

AMARANTE, P. Saúde mental e atenção psicossocial. Rio de Janeiro: Fiocruz, 2007.

BARROS, L. P.; KASTRUP, V. Cartografar é acompanhar processos. In: PASSOS, E.; KASTRUP, V.; ESCÓSSIA, L. (Org.). Pistas do método da cartografia: pesquisa-intervenção e produção de subjetividade. Porto Alegre: Sulinas, 2009. p. 52-75.

CASTRO, E. D. et al. Formação em Terapia Ocupacional na interface das artes e da saúde: a experiência do PACTO. Rev. Ter. Ocup. Univ. São Paulo, São Paulo, v. 20, n. 3, p. 149-156, set./dez. 2009. Cross ${ }^{\text {Ref. }}$

CASTRO, E. D. et al. Território e diversidade: trajetórias da Terapia Ocupacional em experiências de arte e cultura. Cadernos de Terapia Ocupacional, São Carlos, v. 24, n. 1, p. 3-12, 2016. Cross ${ }^{\mathrm{Ref}}$

CASTRO, E. D.; LIMA, L. J. C.; NIGRO, G. M. S. Convivência, trabalho em grupo, formatividade e práticas territoriais na interface arte-saúde-cultura. In: MAXIMINO, V.; LIBERMAN, F. (Org.). Grupos e Terapia ocupacional: formação, pesquisa e ações. São Paulo: Summus, 2015. p. 128-147.

DELEUZE, G. Nietzsche e a filosofia. Rio de Janeiro: Editora Rio, 1976.

DUARTE, R. E. S. T.; INFORSATO, E. A. De que forma. Interface (Botucatu), Botucatu, v. 15, n. 39, p. 1225-1228, out./ dez. 2011. Cross ${ }^{\text {Ref. }}$

EMANUEL ESPERÓN, J. P. O corpo como unidade de dominação: a compreensão deleuziana do elemento trágico da filosofia de Nietzsche. Revista Trágica: estudos sobre Nietzsche, v.6, n.2, p.14-28, jul./dez. 2013. Disponível em: <http://tragica. org/artigos/v6n2/esperon.pdf>. Acesso em: 22 out. 2016. 
FOUCAULT, M. A ética do cuidado de si como prática da liberdade (1984). In: MOTTA, M. B. (Org.). Ética, sexualidade e política. Rio de Janeiro: Forense Universitária, 2004. Coleção Ditos \& Escritos, v. 5, p. 264-287.

FURLAN, A. S. R.; FURLAN, R. Arte, linguagem e expressão na filosofia de Merleau-Ponty. ARS, São Paulo, v. 3, n. 5, p. 3049, jan./jun. 2005. Cross ${ }^{\text {Ref. }}$

HONORATO, C. Mediação na arte contemporânea: posições entre sistemas de valores adversos. Marcelina. Revista do Mestrado em Artes Visuais da Faculdade Santa Marcelina, São Paulo, ano 3, v. 3, p. 52-68, jul./dez. 2009.

INFORSATO, E. A. Caderno de Narrativas. São Paulo, 2016. Arquivo Pessoal.

LOPES, I. C.; VALENT, I. U.; BUELAU, R. M. Encontro Arte, Saúde e Cultura: compartilhando saberes e experiências em interface. Interface (Botucatu), Botucatu, v. 19, n. 53, p. 407416, abr./jun. 2015. Cross ${ }^{\text {Ref. }}$

MIGUEL, M. Guerrilha e resistência em Cévennes. A cartografia de Fernand Deligny e a busca por novas semióticas deleuzo-guattarianas. Revista Trágica: estudos de filosofia da imanência, Rio de Janeiro, v. 8, n. 1, p. 57-71, jan./abr. 2015. Disponível em: <http://tragica.org/artigos/v8n1/miguel.pdf>. Acesso em: 13 out. 2016.

PASSOS, E.; BARROS, R. B. Clínica, política e as modulações do capitalismo. Rev. Lugar Comum, Rio de Janeiro, n. 19-20, p. 159-171, jan./jun. 2004.

PELBART, P. P. Vida capital: ensaios de biopolítica. São Paulo: Iluminuras, 2003.

SPINOZA, B. Ética. Belo Horizonte: Autêntica, 2009.

YASUI, S. A atenção psicossocial e os desafios do contemporâneo: um outro mundo é possível. Cadernos Brasileiros de Saúde Mental, Florianópolis, v.1, n.1, 2009. Disponível em: <http://incubadora.periodicos.ufsc.br/index. php/cbsm/article/view/1005/1122>. Acesso em: 20 out. 2016.

Recebido em: 14 de novembro de 2016 Aceito em: 26 de maio de 2017 